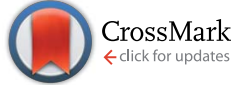

Cite this: J. Mater. Chem. A, 2014, 2 , 18199

Received 13th August 2014 Accepted 9th September 2014

DOI: $10.1039 / c 4 t a 04185 b$

www.rsc.org/MaterialsA

\section{Electronic structural insights into efficient $\mathrm{MnO}_{x}$ catalysts $\uparrow$}

\author{
Munirah Khan, ${ }^{\text {ab }}$ Edlira Suljoti, ${ }^{* a}$ Archana Singh, ${ }^{c}$ Shannon A. Bonke, ${ }^{c}$ \\ Tim Brandenburg, ${ }^{\mathrm{ab}}$ Kaan Atak, ${ }^{\mathrm{ab}}$ Ronny Golnak, ${ }^{\mathrm{ab}}$ Leone Spiccia*c \\ and Emad F. Aziz ${ }^{\star a b}$
}

Soft X-ray absorption and resonant inelastic X-ray scattering at the $\mathrm{Mn}$ L-edge are established as tools for gaining electronic structural insights into water oxidation catalysis. The $\mathrm{MnO}_{x}$ catalyst with the lowest $d-d$ transitions, strongest charge transfer and a higher proportion of $\mathrm{Mn}^{3+}$ over $\mathrm{Mn}^{2+/ 4+}$ produces itinerant electrons that contribute to a higher catalytic activity.

The efficient conversion of solar to chemical energy is possibly the greatest challenge for the scientific community this century. ${ }^{1}$ This energy conversion is performed in nature through photosynthesis, which features a series of redox reactions, the key to which, is the splitting of water. ${ }^{2,3}$ Attempts to mimic this energy storage process have been hindered by energy losses associated with the water oxidation step $\left(2 \mathrm{H}_{2} \mathrm{O} \rightarrow \mathrm{O}_{2}+\right.$ $4 \mathrm{H}^{+}+4 \mathrm{e}^{-}$). Water oxidation is a mechanistically complex redox reaction, which is catalysed in all photosynthetic organisms within the oxygen evolution centre (OEC) of photosystem II (PSII), and contains a $\mathrm{CaMn}_{4} \mathrm{O}_{5}$ cluster. $^{2-6}$ If synthetically achieved such a light-driven water oxidation process could form the basis of technologies that provide us with an abundant and renewable source of fuel. ${ }^{7}$ Manganese is an ideal candidate for research in this area as it is both inexpensive and environmentally friendly. This has been recognised in the literature with bio-inspired Mn catalysts being extensively researched. ${ }^{8-11}$ Manganese oxides $\left(\mathrm{MnO}_{x}\right)$ have been demonstrated to be effective water oxidation catalysts whilst also providing structural and mechanistic clues about the nature of the reaction

\footnotetext{
ajoint Ultrafast Dynamics Lab in Solutions and at Interfaces (JULiq), Helmholtz Zentrum Berlin für Materialien und Energie, Albert-Einstein-Strasse 15, 12489 Berlin, Germany. E-mail: edlira.suljoti@helmholtz-berlin.de

${ }^{b}$ Department of Physics, Freie Universität Berlin, Arnimallee 14, 14159 Berlin, Germany.E-mail: emad.aziz@helmholtz-berlin.de

'School of Chemistry and ARC Centre of Excellence for Electromaterials Science, Monash University, Victoria, 3800, Australia. E-mail: leone.spiccia@monash.edu

$\dagger$ Electronic supplementary information (ES) available: Experimental section, Fig. S1-S5, linear fitting of XAS spectra, and Table S1. See DOI: $10.1039 / \mathrm{c} 4 \mathrm{ta} 04185 \mathrm{~b}$
}

occurring in the OEC..$^{12-19}$ Herein, we complement our previous work with $\mathrm{MnO}_{x}$ by performing X-ray absorption and resonant inelastic X-ray scattering experiments at the Mn L-edge. These studies have been carried out under ex situ conditions at different stages of the catalytic cycle to gain additional insights about the electronic structure of efficient $\mathrm{MnO}_{x}$ catalysts. These catalysts have been generated by doping manganese complexes into a Nafion matrix and applying a potential of $1.0 \mathrm{~V}(\mathrm{vs}$. Ag/ $\mathrm{AgCl}$ ), as previously reported., ${ }^{9,10}$ In our previous work, the manganese complexes were shown to act as precursors to $\mathrm{MnO}_{x}$ nanoparticles, which catalysed water oxidation under benign conditions (pH 6.5). ${ }^{13}$ In this earlier work encompassing K-edge X-ray absorption near edge spectroscopy (XANES), extended Xray absorption fine structure (EXAFS), electron paramagnetic resonance (EPR), transmission electron microscopy (TEM) and electron diffraction studies it was established that disordered $\mathrm{MnO}_{x}$ nanoparticles with a layered birnessite structure were responsible for the catalytic activity. ${ }^{13,20,21}$ In addition, it was found that by using different manganese precursor complexes, the size and catalytic activity of the $\mathrm{MnO}_{x}$ nanoparticles were altered. ${ }^{20}$ Ultra-small nanoparticles ( $\leq 10 \mathrm{~nm}$ diameter) with the highest activity of the series were formed from a Mn(III) dimer complex that was used as a $\mathrm{MnO}_{x}$ precursor. ${ }^{20}$ The effect of the precursors on catalytic activity has been examined, however, the effect that the Mn coordination complex has on the electronic properties of the final catalyst remains unclear. What influence do the $\mathrm{Mn}$ oxidation state and/or ligands in the precursor complex have on the generated $\mathrm{MnO}_{x}$ ?

To gain greater insight into the electronic structure of different catalysts and the effect the reported nanoscale structural disorder has on the Mn oxidation state, we have herein applied resonant inelastic X-ray scattering ${ }^{22,23}$ (RIXS) in combination with X-ray absorption spectroscopy (XAS) at the Mn Ledge. By using L-edge XAS and RIXS it is possible to directly probe the unoccupied and occupied manganese $3 \mathrm{~d}$ electronic valence states, which govern the functionality of the catalysts during water oxidation. X-ray experiments were performed $e x$ situ at different stages of the catalyst generation and water 
oxidation cycle. Within the series of manganese complexes previously shown to generate manganese oxide nanoparticles in Nafion, ${ }^{20}$ three were selected: a $\mathrm{Mn}(\mathrm{II})$ species, $\left[\mathrm{Mn}\left(\mathrm{OH}_{2}\right)_{6}\right]^{2+}$, the dinuclear $\mathrm{Mn}(\mathrm{III})$ complex, $\left[\mathrm{Mn}_{2} \mathrm{O}(\mathrm{OAc})_{2} \mathrm{~L}_{2}\right]^{2+}$, and an $\mathrm{Mn}(\mathrm{IV})$ complex, $\left[\mathrm{MnL}(\mathrm{OMe})_{3}\right]^{+}$(where $\mathrm{L}=\mathrm{Me}_{3} \mathrm{TACN} / 1,4,7$-trimethyl1,4,7-triazacyclononane in both cases). For clarity, these complexes will be referred to as $\mathrm{Mn}$ (II), $\mathrm{Mn}$ (III) and $\mathrm{Mn}$ (IV), respectively. Use of the $\mathrm{Mn}$ (III) complex was shown to generate $\mathrm{MnO}_{x}$ nanoparticles that were the most efficient catalysts in the series, contrasting with the $\mathrm{MnO}_{x}$ produced from the $\mathrm{Mn}$ (II) species which was the least active. ${ }^{20}$

To probe the unoccupied 3d electronic density of states (DOS), the Mn L-edge X-ray absorption (XA) spectra were recorded in total electron yield (TEY) mode, with spectra for the Mn(III) complex shown in Fig. 1. State 1 (as doped) represents the complex doped in the Nafion film, state 2 (as biased) is after applying a $1.0 \mathrm{~V}$ bias ( $v s$. $\mathrm{Ag} / \mathrm{AgCl})$ to the doped film, sufficient to form the active $\mathrm{MnO}_{x}$ catalyst, ${ }^{\mathbf{1 3 2 0}}$ while state 3 (light shined) represents the regenerated catalyst and is a result of photoreduction of the catalyst with visible light for 16 hours. During XA measurements, photon flux was minimized as a precaution against radiation damage of the catalysts from the synchrotron beam (this is detailed in the ESI $\dagger$ ). The XA spectra of the Mn(III) complex are characterised by two broad multiplet structures, $\mathrm{L}_{3}$ and $\mathrm{L}_{2}$ that are separated by spin-orbit coupling. The $\mathrm{L}_{2}$ edge is a broader replica of $\mathrm{L}_{3}$ due to fast Coster-Kronig Auger electron decay. Going from state 1 to state 3 of the catalytic cycle, a pronounced intensity change of the spectral features inherent to the $3 \mathrm{~d}$ orbital occupation and marked with letters "a-f" in Fig. 1 is observed. The spectral features "a", " $b_{1}-b_{2}$ " and "c", located at $640.4 \mathrm{eV}, 642 \mathrm{eV}, 642.8 \mathrm{eV}$ and $644 \mathrm{eV}$ can be associated with contributions of $\mathrm{Mn}^{2+}, \mathrm{Mn}^{3+}$ and $\mathrm{Mn}^{4+}$ oxidation states, respectively. ${ }^{24-26}$ The very high intensity of peak "a" in

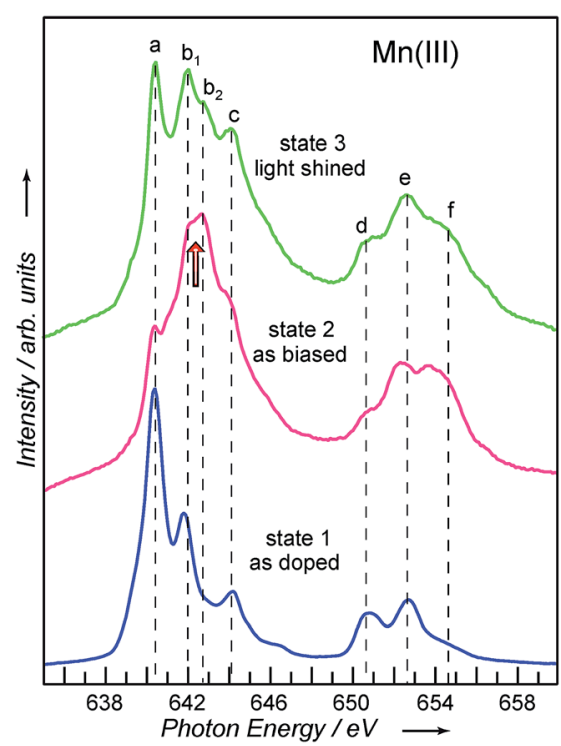

Fig. $1 M n L_{2,3}$-edge XAS of the $M n$ (III) dimer, measured ex situ in TEY at different stages of the catalytic cycle. State 1 (as doped): complex doped in Nafion; state 2 (as biased): active $\mathrm{MnO}_{x}$ catalyst; state 3 (light shined): regenerated catalyst. state 1 indicates a reduction of the $\mathrm{Mn}$ (III) dimer to a $\mathrm{Mn}^{2+}$ like state after doping into Nafion. ${ }^{25,26}$

In order to quantify the mixed oxidation states of the catalysts, we measured Mn L-edge XAS of several reference samples with well-known $\mathrm{Mn}$ oxidation states: $\mathrm{Mn}_{2} \mathrm{O}_{3}\left(\mathrm{Mn}^{3+}\right)$, synthetic birnessite $\left(\mathrm{Mn}^{3+} \& \mathrm{Mn}^{4+}\right)$ and $\mathrm{MnO}_{2}\left(\mathrm{Mn}^{4+}\right)$. The spectra obtained (Fig. 2a) are consistent with previous reports. ${ }^{25}$ The measured L-edge spectra of the different $\mathrm{MnO}_{x}$ catalysts were fitted by a linear combination of $\mathrm{Mn}^{2+}, \mathrm{Mn}^{3+}$ and synthetic birnessite $\left(\mathrm{Mn}^{3+} \& \mathrm{Mn}^{4+}\right)$ spectra.

The experimental and fitted spectra are shown in Fig. $2 b-d$ (fitting coefficients provided in Table S1†). Thus, in the "as biased" state the $\mathrm{MnO}_{x}$ catalysts are in a mixed oxidation state that consists of $60 \% \mathrm{Mn}^{3+}$ and $40 \% \mathrm{Mn}$ birnessite-like for the Mn(III) catalyst; $10 \% \mathrm{Mn}^{3+}$ and $40 \% \mathrm{Mn}$ birnessite-like for the $\mathrm{Mn}$ (II) catalyst and $60 \% \mathrm{Mn}^{3+}$ and $30 \%$ birnessite-like for $\mathrm{Mn}$ (IV) catalyst. The presence of the $30-40 \%$ contribution from a $\mathrm{Mn}$ birnessite-like state for all $\mathrm{MnO}_{x}$ catalysts confirms our previous reports that the catalysts adopt a disordered birnessite structure under oxidative bias. ${ }^{13,21}$ It is interesting to observe the higher proportion of $\mathrm{Mn}^{3+}$-like state in the $\mathrm{MnO}_{x}$ derived from the $\mathrm{Mn}$ (III) and Mn(IV) complexes (Fig. 2b and c respectively). These are the two complexes that show the highest catalytic activity. Contrastingly, the least active catalyst examined, the $\mathrm{Mn}$ (II) precursor catalyst (Fig. 2d) is less oxidised in the "as biased"
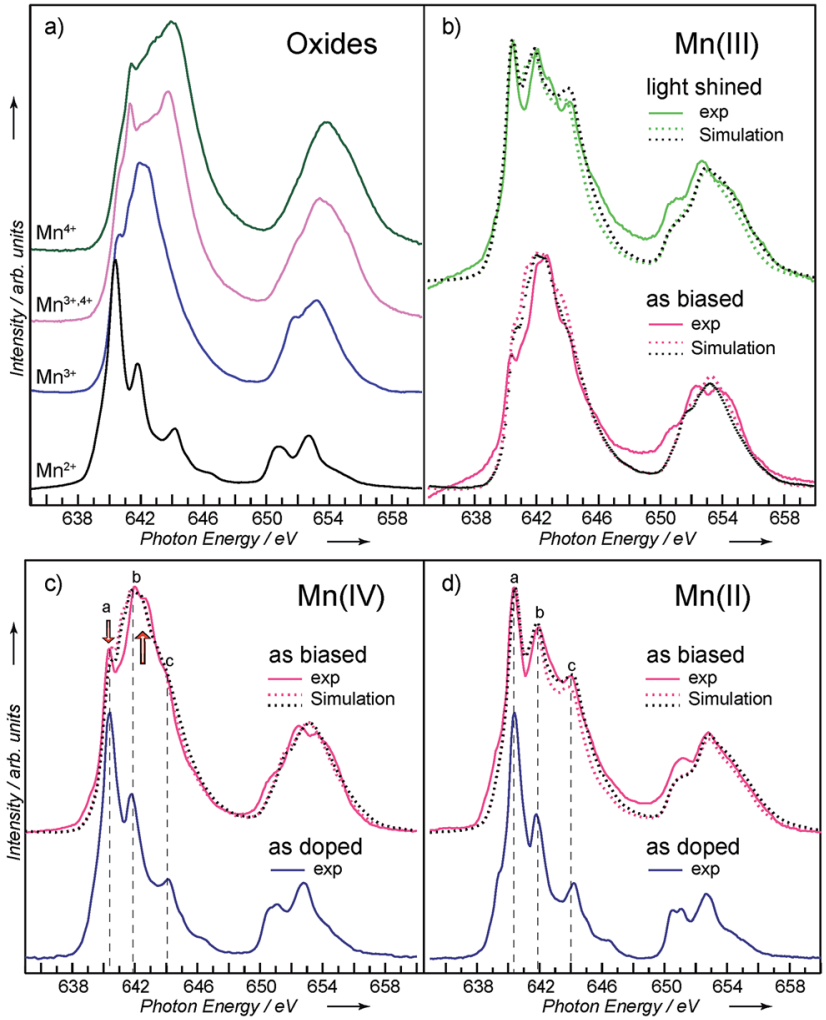

Fig. $2 \mathrm{Mn} \mathrm{L}_{2,3}$-edge XAS measured in TEY of (a) reference $M n$ oxides powders; black: $\mathrm{Mn}(\Perp)$ complex; blue: $\mathrm{Mn}_{2} \mathrm{O}_{3}$; pink: synthetic birnessite; green: $\mathrm{MnO}_{2}$, and of (b-d) $\mathrm{Mn}(\mathrm{II}), \mathrm{Mn}(\mathrm{II})$, and $\mathrm{Mn}(\mathrm{IV})$ catalysts at different catalytic states together with simulated spectra (details are given in Table $\mathrm{S} 1 \uparrow$ ). 
state. ${ }^{20}$ It shows only a $10 \%$ contribution from a $\mathrm{Mn}^{3+}$-like state. $\mathrm{Mn}^{3+}$ has been recognised as an important intermediate state in

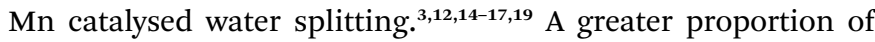
$\mathrm{Mn}^{3+}$ in the structure will coincide with a larger degree of distortion in the local structure, which correlates with an improved catalytic activity. ${ }^{19}$ Separate studies have shown increased catalytic turnover electrochemically by increasing the proportion of $\mathrm{Mn}^{3+}$ in $\mathrm{MnO}_{x}$ nanoparticles. ${ }^{15}$ Regarding the $\mathrm{MnO}_{x}$ formed in Nafion,, ${ }^{9,10,13,20}$ TEM studies have concluded that the disordered birnessite phases generated from the Mn(III) complex have a greater number of Mn vacancies and a higher degree of layer misregistration compared to synthetic birnessite nanoparticles. ${ }^{21}$ Herein, it is shown that $\mathrm{Mn}$ (III) derived $\mathrm{MnO}_{x}$ incorporates a higher content of $\mathrm{Mn}^{3+}$-like states. Previous catalytic studies have shown that $\mathrm{MnO}_{x}$ derived from the $\mathrm{Mn}$ (III) complex is more active towards water oxidation than those from the $\mathrm{Mn}$ (II) or $\mathrm{Mn}(\mathrm{IV})$ complexes. ${ }^{20}$ Correlating the results from these studies indicates that the higher catalytic activity shown by these $\mathrm{Mn}$ (III) derived nanoparticles is likely due to the higher proportion of $\mathrm{Mn}^{3+}$-like states. Such a conclusion would be aligned with previous studies in the literature considering the findings linking $\mathrm{Mn}^{3+}$ with improved catalysis of water oxidation. . $^{12,14-17,19}$

Furthermore, examination of the nitrogen K-edge XAS for the Mn(III) complex (see ESI $\dagger$ ) revealed that some of the $\mathrm{Me}_{3}$ TACN ligands remain coordinated to $\mathrm{Mn}$ ions after doping into Nafion. The presence of the ligands may stabilise the $\mathrm{Mn}^{3+}$-like states allowing a higher proportion of $\mathrm{Mn}^{3+}$-like states. ${ }^{15}$

Applying the same fitting procedure to the XA spectrum of the $\mathrm{MnO}_{x}$ catalyst in state 3 (Fig. 2b), we find that the catalyst is partly photo-reduced. Its mixed oxidation state consists of $45 \%$ $\mathrm{Mn}^{2+}, 15 \% \mathrm{Mn}^{3+}$, and $40 \% \mathrm{Mn}$ birnessite-like state contributions. It is important to note that its birnessite-type phase contribution remains unchanged compared to the "as biased" state, even though photo-reduction converts almost $50 \%$ of the charge from the $\mathrm{Mn}^{3+}$ to $\mathrm{Mn}^{2+}$ oxidation state. This suggests that the distorted $\mathrm{MnO}_{x}$ catalyst derived from the $\mathrm{Mn}$ (III) complex is stable and remains as the active phase in state 2 and state 3 of the catalytic cycle.

Although the greater proportion of $\mathrm{Mn}^{3+}$-like states correlates with catalytic activity, the reason for these activity increases remains unclear. To probe for possible differences in the occupied 3d electronic DOS, we carried out RIXS experiments at the $\mathrm{Mn}$ L-edge. This was performed on the $\mathrm{MnO}_{x}$ catalysts generated from $\mathrm{Mn}$ (III) (most efficient catalyst) and $\mathrm{Mn}$ (II) (least efficient); that is, in state 2 (as biased). The spectra are presented as photon loss features in Fig. 3. The peak located at $0 \mathrm{eV}$ energy loss is due to filling of the $2 \mathrm{p}$ core hole by the excited electron (photon in $=$ photon out), the peaks located at higher energy losses, up to $6 \mathrm{eV}$, are due to filling of the $2 \mathrm{p}$ core hole by an electron from the occupied $3 \mathrm{~d}$ valence states (photon out $<$ photon in) while the peaks located above $8 \mathrm{eV}$ are due to charge transfer transitions. ${ }^{27,28}$ Being fully dipole allowed, RIXS can probe the intensity and energetic position of the occupied $3 \mathrm{~d}$ DOS relative to the empty $3 \mathrm{~d}$ states. In addition, the lowest energetic $d-d$ transition can be a measure of the band gap between the $3 \mathrm{~d}$ valence band maximum (VBM) and the $3 \mathrm{~d}$

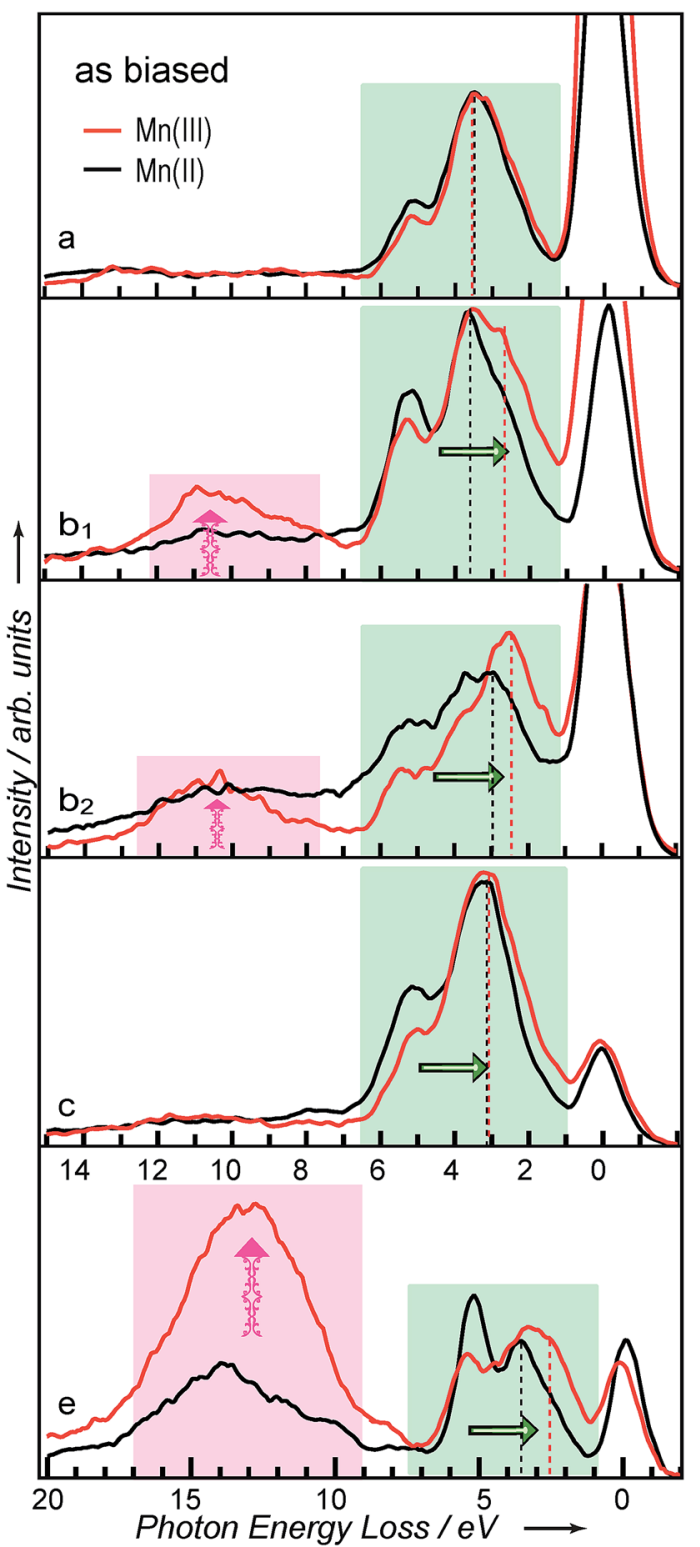

Fig. 3 Experimental RIXS spectra at the $M n L_{2,3}$-edge of $M n(I I)$ and $\mathrm{Mn}$ (II) catalysts in state 2 (as biased) of the catalytic cycle. Red: Mn(II) and black: Mn(॥) RIXS spectra are measured upon excitation at the spectral features marked a-e in the XAS spectra shown in Fig. 1. Charge transfer transitions are highlighted pink and $d-d$ transitions are highlighted green.

conduction band minimum (CBM). Exciting the 2p electron to feature "a" (Fig. 1, corresponding to $\mathrm{Mn}^{2+}$-like state located at $640.4 \mathrm{eV}$ ), we observe similar occupied 3d DOS for both Mn(III) and $\mathrm{Mn}$ (II) systems and a $3 \mathrm{~d}$ band gap of $3.6 \mathrm{eV}$ could be estimated (Fig. 3). Excitation of the 2 p electron at state " $b_{1}$ " (located at $642 \mathrm{eV}$ ) results in a shift of the $3 \mathrm{~d}$ occupied DOS towards lower photon energy losses in Fig. 3.

This shift occurs in both the $\mathrm{Mn}$ (III) and $\mathrm{Mn}$ (II) derived catalysts (state 2, as biased), but is more pronounced in the case of $\mathrm{Mn}$ (III) derived $\mathrm{MnO}_{x}$. Exciting the 2p electron at spectral feature " $b_{2}$ " (Fig. 3), results in the greatest shift in the $3 \mathrm{~d}$ DOS, 
giving rise to a $3 \mathrm{~d}$ CBM-VBM band gap of $2.5 \mathrm{eV}$ for $\mathrm{Mn}$ (III) and 3 eV for Mn(II). In addition, the RIXS spectra excited at XA features " $b_{1}$ " and " $b_{2}$ " show the presence of a higher intensity charge transfer peak located between 8 and $12 \mathrm{eV}$ energy losses for $\mathrm{Mn}$ (III) derived $\mathrm{MnO}_{x}$ in comparison to the $\mathrm{Mn}$ (II) system. These results indicate that the $" b_{1}$ " and $" b_{2}$ " absorption features are the result of mixed unoccupied states of Mn 3d and ligand $2 \mathrm{p}$ states. They are also indicative of the presence of itinerant electrons. This provides an explanation for the much higher photocurrents measured for $\mathrm{Mn}$ (III) derived $\mathrm{MnO}_{x}$ catalysts.

When exciting at $644 \mathrm{eV}$, which would correspond to a $\mathrm{Mn}^{4+}$ like state, the charge-transfer band is missing in both $\mathrm{Mn}$ (III) and Mn(II) derived oxides, whilst they both show the same band gap of $\sim 3 \mathrm{eV}$. It is interesting to note that excitation at peak "e" at the $L_{2}$-edge, which is the broadened replica of " $b_{1}-b_{2}$ " feature at the $\mathrm{L}_{3}$-edge, manifests the same behaviour. An energetic shift of the $3 \mathrm{~d}$ Mn valence states is toward lower energies and a very strong emission extended up to $20 \mathrm{eV}$ energy losses. This is due to a charge transfer transition mixed with a fluorescence contribution. The intensity of this peak for the Mn(III) derived oxide is much greater than that from $\mathrm{Mn}$ (II) in state 2 of the catalytic cycle (Fig. 1). This can again be taken to indicate the itinerant electron and the presence of $2 p$ ligands DOS in the vicinity of manganese metal centres. Bearing in mind that " $b_{1}$ $\mathrm{b}_{2}$ " features correspond to a $\mathrm{Mn}^{3+}$-like state, the correlation between the higher $\mathrm{Mn}^{3+}$ quantity and previously quantified catalytic activity is supported.

In summary, we complement our previous work by performing X-ray absorption and resonant inelastic X-ray scattering experiments at the Mn L-edge. These techniques were applied under ex situ conditions at different stages of the catalytic cycle to gain additional electronic structural insights into the $\mathrm{MnO}_{x}$ catalysts. Whilst each of the examined precursor complexes forms nanoparticles with a disordered birnessite phase, they show distinct differences in their electronic structure. We establish that the $\mathrm{Mn}$ centres in the $\mathrm{MnO}_{x}$ nanoparticles are highly oxidised and that the ratio of Mn oxidation states varies $\left(\mathrm{Mn}^{2+}, \mathrm{Mn}^{3+}\right.$, and $\left.\mathrm{Mn}^{4+}\right)$, with the most active catalyst showing a higher proportion of $\mathrm{Mn}^{3+}$ over the $\mathrm{Mn}^{2+/ 4+}$ like states. Furthermore, the RIXS experiments indicated that $\mathrm{Mn}^{3+}$-like states have the lowest local HOMO-LUMO gap (a d-d transition energy of $2.5 \mathrm{eV}$ ) of the Mn sites present. The $\mathrm{Mn}^{3+}$ like states also display the strongest intensity charge transfer emission band compared to the $\mathrm{Mn}^{2+/ 4+}$-like states. These facts point to the presence of itinerant electrons and ligand 2p DOS in the vicinity of manganese centre.

\section{Acknowledgements}

This work was supported by the Helmholtz-Gemeinschaft via the young investigator fund VH-NG-635 and the European Research Council Starting Grant \#279344. Munirah Khan acknowledges the financial support from the Higher Education Commission of Pakistan and Deutscher Akademischer Austauschdienst for a doctoral scholarship. Leone Spiccia acknowledges the Alexander von Humboldt Foundation for a Senior Research Award and financial support from the
Australian Research Council through the Australian Centre of Excellence for Electromaterials Science.

\section{Notes and references}

1 N. Armaroli and V. Balzani, Angew. Chem., Int. Ed., 2007, 46, 52-66.

2 J. P. McEvoy and G. W. Brudvig, Chem. Rev., 2006, 106, 44554483.

3 M. Wiechen, M. M. Najafpour, S. I. Allakhverdiev and L. Spiccia, Energy Environ. Sci., 2014, 7, 2203-2212.

4 K. N. Ferreira, T. M. Iverson, K. Maghlaoui, J. Barber and S. Iwata, Science, 2004, 303, 1831-1838.

5 J. Yano, J. Kern, K. Sauer, M. J. Latimer, Y. Pushkar, J. Biesiadka, B. Loll, W. Saenger, J. Messinger, A. Zouni and V. K. Yachandra, Science, 2006, 314, 821-825.

6 Y. Umena, K. Kawakami, J.-R. Shen and N. Kamiya, Nature, 2011, 473, 55-60.

7 J. Barber, Chem. Soc. Rev., 2009, 38, 185-196.

8 J. Limburg, J. S. Vrettos, L. M. Liable-Sands, A. L. Rheingold, R. H. Crabtree and G. W. Brudvig, Science, 1999, 283, 15241527.

9 R. Brimblecombe, G. F. Swiegers, G. C. Dismukes and L. Spiccia, Angew. Chem., Int. Ed., 2008, 47, 7335-7338.

10 R. Brimblecombe, A. Koo, G. C. Dismukes, G. F. Swiegers and L. Spiccia, J. Am. Chem. Soc., 2010, 132, 2892-2894.

11 M. Wiechen, I. Zaharieva, H. Dau and P. Kurz, Chem. Sci., 2012, 3, 2330-2339.

12 Y. Gorlin and T. F. Jaramillo, J. Am. Chem. Soc., 2010, 132, 13612-13614.

13 R. K. Hocking, R. Brimblecombe, L. Y. Chang, A. Singh, M. H. Cheah, C. Glover, W. H. Casey and L. Spiccia, Nat. Chem., 2011, 3, 461-466.

14 T. Takashima, K. Hashimoto and R. Nakamura, J. Am. Chem. Soc., 2012, 134, 1519-1527.

15 T. Takashima, K. Hashimoto and R. Nakamura, J. Am. Chem. Soc., 2012, 134, 18153-18156.

16 I. Zaharieva, P. Chernev, M. Risch, K. Klingan, M. Kohlhoff, A. Fischer and H. Dau, Energy Environ. Sci., 2012, 5, 70817089.

17 Y. Gorlin, B. Lassalle-Kaiser, J. D. Benck, S. Gul, S. M. Webb, V. K. Yachandra, J. Yano and T. F. Jaramillo, J. Am. Chem. Soc., 2013, 135, 8525-8534.

18 A. Indra, P. W. Menezes, I. Zaharieva, E. Baktash, J. Pfrommer, M. Schwarze, H. Dau and M. Driess, Angew. Chem., Int. Ed., 2013, 52, 13206-13210.

19 J. Park, H. Kim, K. Jin, B. J. Lee, Y.-S. Park, H. Kim, I. Park, K. D. Yang, H.-Y. Jeong, J. Kim, K. T. Hong, H. W. Jang, K. Kang and K. T. Nam, J. Am. Chem. Soc., 2014, 136, 42014211.

20 A. Singh, R. K. Hocking, S. L. Y. Chang, B. M. George, M. Fehr, K. Lips, A. Schnegg and L. Spiccia, Chem. Mater., 2013, 25, 1098-1108.

21 S. L. Y. Chang, A. Singh, R. K. Hocking, C. Dwyer and L. Spiccia, J. Mater. Chem. A, 2014, 2, 3730-3733.

22 M. M. van Schooneveld, R. W. Gosselink, T. M. Eggenhuisen, M. Al Samarai, C. Monney, K. J. Zhou, T. Schmitt and 
F. M. F. de Groot, Angew. Chem., Int. Ed., 2013, 52, 11701174.

23 E. Suljoti, R. Garcia-Diez, S. I. Bokarev, K. M. Lange, R. Schoch, B. Dierker, M. Dantz, K. Yamamoto, N. Engel, K. Atak, O. Kühn, M. Bauer, J.-E. Rubensson and E. F. Aziz, Angew. Chem., Int. Ed., 2013, 52, 9841-9844.

24 S. P. Cramer, F. M. F. DeGroot, Y. Ma, C. T. Chen, F. Sette, C. A. Kipke, D. M. Eichhorn, M. K. Chan and W. H. Armstrong, J. Am. Chem. Soc., 1991, 113, 7937-7940.

25 B. Gilbert, B. H. Frazer, A. Belz, P. G. Conrad, K. H. Nealson, D. Haskel, J. C. Lang, G. Srajer and G. De Stasio, J. Phys. Chem. A, 2003, 107, 2839-2847.
26 A. Galdi, C. Aruta, P. Orgiani, N. B. Brookes, G. Ghiringhelli, M. Moretti Sala, R. V. K. Mangalam, W. Prellier, U. Lüders and L. Maritato, Phys. Rev. B: Condens. Matter Mater. Phys., 2011, 83, 064418.

27 G. Ghiringhelli, M. Matsubara, C. Dallera, F. Fracassi, A. Tagliaferri, N. Brookes, A. Kotani and L. Braicovich, Phys. Rev. B: Condens. Matter Mater. Phys., 2006, 73, 035111.

28 M. Magnuson, L. C. Duda, S. M. Butorin, P. Kuiper and J. Nordgren, Phys. Rev. B: Condens. Matter Mater. Phys., 2006, 74, 172409. 